\title{
Development and Validation of Organizational Citizenship Behaviours Scale (OCBS) for the Nigerian Context
}

\author{
Elizabeth I. Olowookere', Grace A. Adejuwon² \\ ${ }^{1}$ College of Leadership Development Studies, School of Human Resource Development, Department of \\ Psychology, Covenant University, Ota, Nigeria \\ ${ }^{2}$ Department of Psychology, Faculty of the Social Sciences, University of Ibadan, Oyo State, Nigeria \\ Email: elizabeth.olowookere@covenantuniversity.edu.ng, anuadejuwon@yahoo.com
}

Received 9 February 2015; accepted 3 April 2015; published 8 April 2015

Copyright (C 2015 by authors and Scientific Research Publishing Inc.

This work is licensed under the Creative Commons Attribution International License (CC BY). http://creativecommons.org/licenses/by/4.0/

(c) ()

\section{Abstract}

This study examined key dimensions of organizational citizenship behaviours in the Nigerian context and validated appropriate measure of the construct in Nigeria. One hundred (100) employees comprising of forty seven (47) males and fifty three (53) females from public and private organizations in Lagos State participated in this study. Consequent upon the cultural sensitivity of organizational citizenship behaviour dimensions, Organizational Citizenship Behaviours Scale (OCBS) was validated as a suitable measure of $O C B$ in the Nigerian context. Factor analysis was used to identify the specific dimensions of the OCBS to include: Organizational Involvement (OI), Dutifulness (D) and Interpersonal Relationship (IR), consisting nine (9), nine (9) and twelve (12) items respectively. The KMO measure of sampling adequacy showed a value of .59 . This value simply shows that the sample of $\mathbf{1 0 0}$ participants was adequate to conduct factor analysis on the OCBS. The Bartlett's test of Sphericity showed a significant value $\left(x^{2}(1830)=3578.981, p<.001\right)$. The 30 item OCBS scale has a Cronbach alpha of .86, the Dutifulness sub-scale .74, the Interpersonal Relationship .75 and the Organizational involvement .88. The convergent validity between OCBS and the Intrinsic Religiosity dimension of the Religious Orientation Scale developed by Allport and Ross (1967) was found to be significant at .01. This paper concluded and recommended that the dimension of generalized compliance is vital to the measure of organizational citizenship behaviours in the Nigerian context and should not be underplayed.

\section{Keywords}

Organizational Citizenship Behaviour, Organizational Involvement, Dutifulness, Interpersonal Relationship, Nigeria 


\section{Introduction}

Organizational citizenship behaviours (OCB) are those desirable employee behaviours that are not enforceable by the organization, though essential for effective work processes and the smooth running of the organization. Bateman and Organ (1983) and Smith, Organ and Near (1983) founded their idea of organizational citizenship behaviour on the concept of "willingness to cooperate" proposed by Barnard (1938) and the concepts of dependable role performance and "innovative and spontaneous behaviours" described by Katz (1964) and Katz and Kahn (1966). Smith et al. (1983) identified two types of organizational citizenship behaviours to include altruism (benevolence) and generalized compliance (adherence to rules). However, Organ (1988) redefined OCB to refer to extra role behaviours and subsequently revised its dimensions to include altruism, civic virtue (concern and keen interest in the affairs of the organization), conscientiousness (a display of diligence and resourcefulness on the part of employees), courtesy (consideration and respect for others) and sportsmanship (positive attitude and tolerance for the inevitable inconveniences associated with work without complaining). The generalized compliance dimension was submerged into conscientiousness while altruism was retained as originally proposed.

Williams and Anderson (1991) identified three dimensions of OCB to include in-role behaviours (IRB), organizational citizenship behaviours directed at the organization (OCBO) and organizational citizenship behaviours directed at the individuals within the organization (OCBI). The in-role behaviours represent stipulated duties contained in the job description and employment contract. This set of behaviours is similar to the dependable role performance posited by Katz (1964). The OCBO dimension encapsulates conscientiousness, sportsmanship and civic virtue dimensions as posited by Organ (1988), while OCBI consists of courtesy and altruism dimensions as posited by Organ (1988).

Liu, Huang and Chen (n.d) noted that despite the cultural sensitivity of organizational citizenship behaviours, most empirical research on OCB were based on American values. Consequently, Al-sharafi and Rajiani (2013) suggested the need to conduct OCB studies in different contexts and apply their findings appropriately. Every context has its own culture marked by unique values, beliefs and behavioural patterns. While some dimensions of organizational citizenship behaviours are considered to be universal across contexts, others are specific to particular contexts.

The attitude of many employees in Nigeria may be described using McGregor's theory $\mathrm{X}$ in which they are naturally assumed to be lazy and unambitious, hence the constant use of sanctions and control. Consequently, Nigerian managers may value the generalized compliance dimension of the OCB as peculiar to their context. Organ (1983) defined this dimension as doing what a good employee should do. When Nigerian workers willingly obey stipulated organizational rules and regulations without any form of threat or sanctions, they may be considered as good organizational citizens. Therefore, OCB in the Nigerian context is not just about extra role behaviours but employees' voluntary devotion to organizational rules, processes and standards without being monitored or coerced.

\section{Literature Review}

Different theories have been propounded in an attempt to explain employee motivations and work behaviours. From the perspective of the social exchange theory (first introduced by George Homans in the late 1950s), employee work behaviour is based on mutually desirable and beneficial relationships. On the premise of trust, employees initiate a good deed in anticipation that such will be reciprocated in due course, although what, when and how it will be reciprocated are not stated. Likewise, the recipient of the favour also feels a sense of obligation to reciprocate this gesture based on the idea that one good turn deserves another. This is a tit for tat interaction in which employees trade favours and good deeds. However, this exchange of favours is not limited to employee-employee interactions but also employee-organization interactions. Once employees receive favours from the organization, they usually feel obligated to reciprocate, and consequently engage in what is now called organizational citizenship behaviour. These employees become loyal to the organization and willingly express their commitment to it.

Management assumptions and practices have also been implicated in employee behaviours (McGregor, 1960; Ouchi, 1981). Traditionally, managers hold a pessimistic view of employees' attitude to work; they see employees as lazy, profit seeking and requiring coercion to get work done. This is descriptive of theory X propounded by McGregor (1960). He posited that management believes that workers need to be closely supervised 
and comprehensive systems of controls developed if organizational goals are to be achieved. However, this type of practice will only result in forced compliance and average performance from the employees. As a result, McGregor (1960) posited the theory Y which holds an optimistic view of employee attitudes and behaviours, stating that under the right conditions employees will act responsibly and take initiative for self-development and increased organizational outcomes. Theory Y fosters employee commitment and improved performance and organizational profit.

Theory Z was posited by Ouchi (1981) with a much more optimistic view of employee behaviours and attitudes. It emphasized collectivism, participative decision making, mutual responsibilities and mutual benefits between management and the employees. Theory $\mathrm{Z}$ managers see to the welfare of their employees and express concern for their personal and family life, consequently employees reciprocate this gesture through their loyalty and allegiance to the organization.

Based on the assumptions of Theory X, many employees in Nigeria have been described as naturally lazy and unambitious. This explains the constant use of sanctions and control in Nigerian organizations. However, some managers still have an optimistic opinion of the Nigerian workforce and have therefore adopted the Theory Y assumptions of their employees. Here they are seen as responsible and willing to work when given the needed environment. The Theory Y assumptions may be considered as the best view Nigerian managers have of their employees. For many managers, the Theory $\mathrm{Z}$ assumptions which emphasizes employee participation and partnership are mere wishes and somewhat too good to be true.

Consequently, because of these assumptions about employees, Nigerian managers may value the general compliance dimension of the OCB as peculiar to their context. Organ (1983) defined this dimension as doing what a good employee should do. Although the extra role behaviours are appreciated, voluntary adherence to organizational rules and regulations may be considered a vital dimension of OCB in Nigeria. When workers willingly obey stipulated organizational rules and regulations without any form of threat or sanctions, they may be considered as good organizational citizens. Therefore, OCB may be defined in the Nigerian context as consisting of generalized compliance (GC) and extra role behaviours (ERB) independent of all forms of threats and sanctions. This postulation is explained in the equation below:

$$
\mathrm{OCB}=\mathrm{GC}+\mathrm{ERB}
$$

This implies that OCB in the Nigerian context is a function of going above and beyond the call of duty and the voluntary adherence to organizational rules and policies. The current study proposed a three dimension measure of organizational citizenship behaviour to include measures of Interpersonal Relationship (IR), Dutifulness (D) and Organizational Involvement (OI). The interpersonal relationship dimension comprises of all behaviours that promote harmony at work and improve employee performance in the organization. This dimension is similar to Williams and Anderson's OCBI (Williams \& Anderson, 1991) and Organ’s (1988) altruism and courtesy (Organ, 1988).

The dutifulness dimension comprises of all behaviours that reflect employees' voluntary adherence to organizational rules, principles and work procedures. This dimension is similar to the conscientiousness dimension proposed by Organ (1988) and the dependable role performance and innovative and spontaneous behaviours proposed by Katz (1964) and Katz and Kahn (1966). Finally, the organizational involvement dimension incorporates employee behaviours aimed at enhancing organizational effectiveness and a positive organizational image. Williams and Anderson (1991) described these behaviours as organizational citizenship behaviours directed at the organization (OCBO), while Organ (1988) described it as civic virtue and sportsmanship.

\section{Method}

A three dimensional organizational citizenship behaviour scale (OCBS) was developed specifically for the Nigerian work context. This involved the generation of a large pool of items from the review of literature and consultation with subject matter experts (SMEs) for content validation of the items. A total of sixty-one (61) items were endorsed by the SMEs and administered to a sample representative of the target population (Nigerian workforce) through the convenient sampling method. The validation sample included healthcare workers from Covenant University Health Centre, teachers from Iganmode Grammar School, staff of Federal Inland Revenue Services (FIRS), MTN Nigeria, Lagos State House of Assembly and Nigerite Plc.

Forty seven (47) males and fifty three (53) females participated in this study, of which $1 \%$ was reported to be less than 20 years of age, 17\% were between 21 - 25 years of age, $29 \%$ were between 26 - 30 years of age, 36\% 
were between 31 - 40 years of age and $17 \%$ were above 40 years of age. Also, $78 \%$ of the participants were Christians and 21\% were Muslims; 70\% of the participants were married while the remaining 30\% were single. A total of 111 questionnaires were administered to these participants but only 108 were retrieved and eight were discarded due to improper completion of the questionnaire. One hundred (100) questionnaires were analyzed to validate the scale and obtain its psychometric properties.

\section{Results}

Factor analysis was conducted to ascertain the dimensions of the OCBS. This involved four stages as follows: determining the appropriateness of factor analysis for the OCBS, establishing the factors or components of the OCBS, factor rotation and labelling the OCBS components. The first stage involved the use of the Bartlett's test of Sphericity and Kaiser-Meyer-Olkin (KMO) to measure sampling adequacy. The KMO measure of sampling adequacy showed a value of .59. This value simply shows that the sample of 100 participants was adequate to conduct factor analysis on the OCBS. The Bartlett's test of Sphericity showed a significant value $\left(x^{2}(1830)=\right.$ 3578.981, $p<.001$ ). The principal component analysis was carried out on the 61 items of the OCBS to identify its principal dimensions. Three principal factors were identified and items that loaded significantly on more than one factor were dropped resulting in a total of 30 items. A confirmatory principal component analysis on the 30 items of the OCBS revealed a KMO of .650 and a significant value of $\left(x^{2}(435)=958.243, p<.001\right)$ on the Bartlett's test of Sphericity. Varimax rotation was carried out to ensure that each of the items loaded significantly and distinctly on one of the three factors to which they are most relevant. The loading of the items is depicted in Figure 1.

From the result of the varimax rotation, the items that loaded under each component of the OCBS were identified and labelled appropriately. The components of the OCBS include: Organizational Involvement (OI), Dutifulness (D) and Interpersonal Relationship (IR) consisting nine (9), nine (9) and twelve (12) items respectively as depicted in Table 1.

The OCBS was further validated with the intrinsic religiosity dimension of the Religious Orientation Scale (ROS) developed by Allport and Ross (1967). The ROS comprises of two dimensions which are intrinsic religiosity and extrinsic religiosity. Intrinsic religiosity is an expression of the beliefs and internalized principles founded on one's faith. It is the act of living out one's religious beliefs and values. On the contrary, extrinsic re-

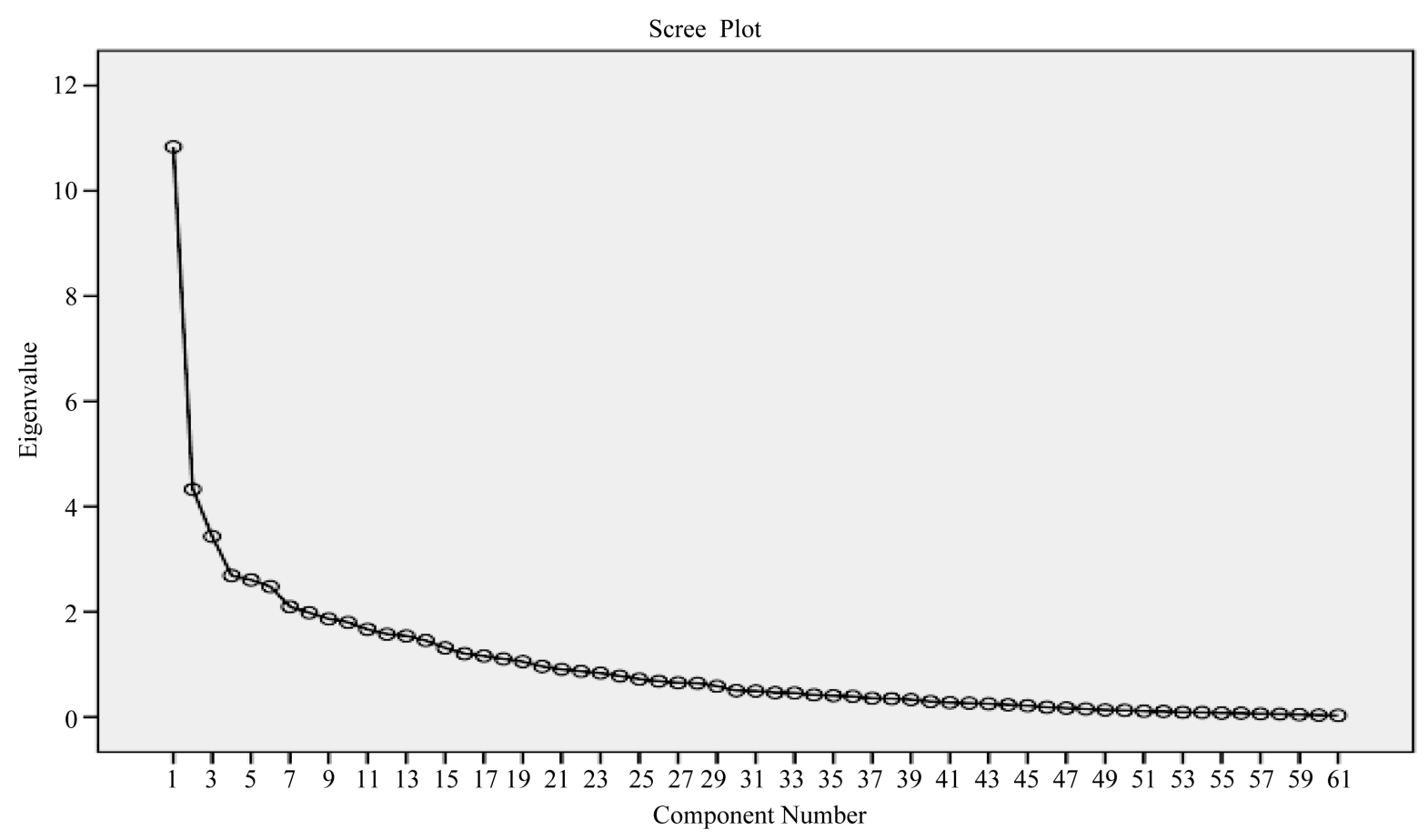

Figure 1. Scree plot showing the factor loading of the 61 items of the OCBS and its 3 most distinct components. 
Table 1. Factor loadings and communalities on the OCBS with varimax rotation.

\begin{tabular}{|c|c|c|c|c|c|}
\hline & \multirow[t]{2}{*}{ Items } & \multicolumn{3}{|c|}{ Components } & \multirow[t]{2}{*}{ Communalities } \\
\hline & & OI & D & IR & \\
\hline 49 & I assist new employees settle on the job & .618 & & & .768 \\
\hline 52 & $\begin{array}{l}\text { I dress and comport myself in ways that positively reflect my } \\
\text { organization }\end{array}$ & .630 & & & .736 \\
\hline 53 & I do my best to reduce wastage of company’s resources & .493 & & & .731 \\
\hline 54 & I act on behalf of my organization in relating with clients & .672 & & & .774 \\
\hline 57 & I regard organization's special dates and events & .573 & & & .825 \\
\hline 59 & $\begin{array}{l}\text { I speak positively about my organization whenever I have the } \\
\text { opportunity }\end{array}$ & .527 & & & .677 \\
\hline 44 & $\begin{array}{l}\text { I believe that when there is so much to accomplish then work must } \\
\text { continue }\end{array}$ & .442 & & & .768 \\
\hline 42 & $\begin{array}{l}\text { I consider every challenge on my job as a torment from my } \\
\text { supervisor }\end{array}$ & .577 & & & .755 \\
\hline 13 & $\begin{array}{l}\text { I feel a sense of fulfilment when our clients/customers are happy } \\
\text { with our services/products }\end{array}$ & .391 & & & 683 \\
\hline 38 & I grudgingly execute tedious assignments & & .706 & & .663 \\
\hline 39 & I give up my lunch break to meet a deadline & & .595 & & .678 \\
\hline 34 & I put in extra hours at work & & .555 & & .815 \\
\hline 35 & I take on extra assignments without protests & & .451 & & .834 \\
\hline 1 & I volunteer to work on assignments during my free time & & .391 & & .735 \\
\hline 2 & I go the extra mile in my effort to satisfy my clients & & .441 & & .815 \\
\hline 3 & I do nothing short of my best in my work assignments & & .430 & & .591 \\
\hline 5 & I assist clients even when it is past working hours & & .426 & & .578 \\
\hline 40 & I comply with unfavourable organizational policies and procedures & & .525 & & .601 \\
\hline 25 & $\begin{array}{l}\text { I help co-workers with logistics during official events or } \\
\text { presentations }\end{array}$ & & & .424 & .769 \\
\hline 27 & $\begin{array}{l}\text { I warn co-workers of any challenge they are likely to face in the } \\
\text { line of duty }\end{array}$ & & & .386 & .719 \\
\hline 33 & I refuse to stand in for co-workers when they leave their duty posts & & & .490 & .744 \\
\hline 14 & I render financial assistance to my co-workers & & & .373 & 620 \\
\hline 15 & I adjust my work schedule to favour my co-workers & & & .609 & .769 \\
\hline 16 & I counsel co-workers on personal matters & & & .549 & 636 \\
\hline 18 & I help my co-worker(s) pick their children from school & & & .578 & .743 \\
\hline 19 & I give gifts to co-workers on their special days & & & .369 & .738 \\
\hline 20 & I buy lunch for co-workers & & & .563 & .580 \\
\hline 22 & I lend my car and other personal properties to co-workers & & & .636 & .693 \\
\hline 23 & $\begin{array}{l}\text { I honour party invitations from co-workers even when it is } \\
\text { convenient }\end{array}$ & & & .504 & .747 \\
\hline 24 & I buy “aso ebi” from co-workers during special occasions & & & .369 & .718 \\
\hline
\end{tabular}


Table 2. Showing the correlation between OCBS and the Intrinsic Religiosity dimension of the ROS.

\begin{tabular}{ccc}
\hline & OCBS & Intrinsic Religiosity \\
\hline OCBS & $.507^{* *}$ \\
Intrinsic religiosity & $.507^{* *}$ & \\
${ }^{* *}$ Correlation is significant at the .01 level (2-tailed). &
\end{tabular}

ligiosity is superficial, involving the demonstration of religious practices to earn the attached benefits. Therefore, intrinsic religiosity is more associated with organizational citizenship behaviours and a very suitable estimate of convergent validity. The correlation between OCBS and intrinsic religiosity dimension of the Religious Orientation Scale was significant at .001. The result is illustrated in Table 2.

This result was supported by the findings of Rastgar, Zarei, Davoudi and Fartash (2012) on the link between workplace spirituality, organizational citizenship behaviour and job performance. They found workplace spirituality to exert significant positive influence on organizational citizenship behaviour $(\mathrm{t}=7.16, p<.05)$ and job performance ( $\mathrm{t}=2.71, p<.05)$; Similarly, Khalid, Rahman and Madar (2013) found intrinsic religiosity to significantly predict OCBO $(\beta=.24, P<.01)$ and extrinsic religiosity to significantly significant predictor of OCBI $(\beta=.29, P<.01)$. The implication of this is that intrinsically religious employees engage in OCBO as a lifestyle without expecting or demanding any benefit in return. They simply seek the good of all. On the other hand, extrinsically religious employees target specific individuals with the aim of trading favours. McGhee and Grant (2008) mentioned that studies have associated workplace spirituality with enhanced teamwork; greater demonstration of kindness, fairness and honesty in the workplace and increased demonstration of organizational citizenship behaviour among others.

\section{Conclusion and Recommendation}

Organizational citizenship behaviour in the Nigerian context is a combination of generalized compliance and extra role behaviours which will be adequately measured by the proposed three dimensional model of OCB, having such dimensions as interpersonal relationship, dutifulness and organizational involvement. These three dimension model of OCB will serve as a valid measure of organizational citizenship behaviour in the Nigerian context having duly emphasized generalized compliance and the extra role behaviours implicated in the dutifulness, interpersonal relationship and organizational involvement dimensions.

Conclusively, work behaviours are categorized as OCB only when they are completely voluntary and culminate in beneficial outcomes for both the individual employees and the organization as a whole. It was therefore recommended that these three dimension model of OCB be adopted and empirically tested for the Nigerian work context.

\section{References}

Allport, G., \& Ross, J. M. (1967). Personal Religious Orientation and Prejudice. Journal of Personality and Social Psychology, 5, 432-443. http://dx.doi.org/10.1037/h0021212

Al-sharafi, H., \& Rajiani, I. (2013). Promoting Organizational Citizenship Behaviour among Employees: The Role of Leadership Practices. International Journal of Business and Management, 8, 47-54.

Bateman, T. S., \& Organ, D. W. (1983). Job Satisfaction and the Good Soldier: The Relationship between Affect and Employee Citizenship. Academic and Management Journal, 26, 587-595. http://dx.doi.org/10.2307/255908

Homans, G. C. (1958). Social Behavior as Exchange. American Journal of Sociology, 63, 597-606. http://dx.doi.org/10.1086/222355

Katz, D. (1964). The Motivational Basis of Organizational Behavior. Behavioral Science, 9, 131-133. http://dx.doi.org/10.1002/bs.3830090206

Katz, D., \& Kahn, R. L. (1966). The Social Psychology of Organizations. New York: Wiley.

Khalid, S. A., Rahman, N. A., \& Madar, A. R. S. (2013). Undergraduates' Organizational Citizenship Behaviour: The Role of Religiosity. International Journal of Academic Research in Business and Social Sciences, 3, 574-584. http://dx.doi.org/10.6007/IJARBSS/v3-i7/78

Liu, C., Huang, P., \& Chen, C. (n.d). Organizational Citizenship Behaviour in a Non-U.S. Context: Its Dimensions, Antece- 
dents and Consequences. http://jgxy.usx.edu.cn/daom/056_chiweiliu.pdf

McGhee, P., \& Grant, P. (2008). Spirituality and Ethical Behaviour in the Workplace: Wishful Thinking or Authentic Reality. Electronic Journal of Business Ethics and Organization Studies, 13, 61-69.

McGregor, D. (1960). The Human Side of the Enterprise. New York: McGraw-Hill, Inc.

Organ, D. W. (1988). Organizational Citizenship Behaviour: The Good Soldier Syndrome. Lexington, MA: Lexington.

Ouchi, W. G. (1981). Theory Z. New York: Avon Books.

Rastgar, A. A., Zarei, A., Davoudi, S. M. M., \& Fartash, K. (2012). The Link between Workplace Spirituality, Organizational Citizenship Behavior and Job Performance in Iran. Arth Prabhand: A Journal of Economics and Management, 1, 51-67.

Smith, C. A., Organ, D. W., \& Near, J. P. (1983). Organizational Citizenship Behaviour: Its Nature and Antecedents. Journal of Applied Psychology, 68, 653-663. http://dx.doi.org/10.1037/0021-9010.68.4.653

Williams, L. J., \& Anderson, S. E. (1991). Job Satisfaction and Organizational Commitment as Predictors of Organizational Citizenship and In-Role Behaviors. Journal of Management, 91, 601-617. http://dx.doi.org/10.1177/014920639101700305 